\title{
Humanitarian Logistics: A Clustering Methodology for Assisting Humanitarian Operations
}

\author{
Fabiana Santos Lima', Daniel de Oliveira², Mirian Buss Gonçalves ${ }^{3}$, Márcia Marcondes Altimari Samed ${ }^{4}$
}

\begin{abstract}
In this paper, we propose a methodology to identify and classify regions by the type and frequency of disasters. The data on the clusters allow you to extract information that can be used in the preparedness phase as well as to identify the relief items needed to meet each cluster. Using this approach, the clusters are formed by using a computing tool that uses as the input the history data of the disasters in the Brazilian state of Santa Catarina, with a specific focus on: windstorms, hail, floods, droughts, landslides, and flash floods. The results show that the knowledge provided by the clustering analysis contributes to the decision making process in the response phase of Humanitarian Logistics (HL).
\end{abstract}

Keywords: humanitarian logistics; clusters; natural disasters; preparedness and response; procurement of relief supplies.

\footnotetext{
1,2,3Programa de Pós-Graduação em Engenharia de Produção.Universidade Federal de Santa Catarina, Brasil. (Principal contact for correspondence E-mail: fabiana.lima@posgrad.ufsc.br)

${ }^{4}$ Departamento de Engenharia de Produção Universidade Estadual de Maringá, Brasil.

ISSN: 07I8-2724. (http://www.jotmi.org)

Journal of Technology Management \& Innovation (c) Universidad Alberto Hurtado, Facultad de Economía y Negocios.
} 


\section{Introduction}

Studies about Humanitarian Logistics (HL) focus on a range of disasters that include earthquakes, tsunamis, hurricanes, epidemics, floods, droughts, famine, terrorist attacks and wars situations as well as the combination of various disasters that can occur simultaneously (Kovács and Spens, 2007). Humanitarian Logistics consists of a set of activities that include: preparedness, planning, procurement, storage, transportation, either of relief goods or information, from the point of origin to the point of consumption with the purpose of relieving the suffering of vulnerable people (Thomas, 2004). In this context, one of the challenges of the preparedness phase is to be able to anticipate the information about the occurrence likelihood of a disaster and its consequences to formulate the response planning and coordinating of the necessary actions. In this paper, we propose a methodology that can be used in the preparedness phase in order to improve the response to natural disasters. Our key objective is to identify and classify similar regions by type and frequency of disasters and to identify what is required in terms of relief goods. Methodologically, the first step in this study is the use of a computing tool for formatting clusters from the historical data of disaster in the Brazilian State of Santa Catarina. The second step is to identify the type of relief supplies normally acquired during the response to the disaster. Finally, we present a case study to illustrate the application in a real disaster, where heavy rain left cities submerged and several families homeless. In this context, we show performance of this methodology in the agility of its response to the disaster. Related Literature

Humanitarian Logistics proposes the effective use of logistics concepts adapted to the specific chain of humanitarian assistance. These concepts can be the big difference in minimizing actions of improvisation, very common in these instances, maximizing efficiency and response time to the emergency situation. However, HL has to deal with special circumstances and enormous challenge (Meirim, 2007). The specific feature in this context is the involvement of human life, which depends on the efficient and effective performance of the response operations, which means that in the $\mathrm{HL}$, the aid must reach its destination accurately and on time, always focusing in the relief of suffering and in the preservation of life. Aspects linked to infrastructure, assistance centres location, resources allocation, coordination of processes (people, information, and goods) are worth mentioning in the logistic processes systematized in the HL.

Many authors highlight the difference between business sector supply chain logistics and HL. Fundamentally, there are crucial points where business logistics differs from HL. Balcik and Beamon (2008) summarize the crucial characteristics of $\mathrm{HL}$ (as different from business logistics), which are de- scribed as follows: unpredictability of demand, in terms of timing, location, type, and size; suddenness of the occurrence of demand in large amounts but with short lead, times for a wide variety of supplies; high stakes associated with the timeliness of deliveries; and lack of resources in terms of the supply, people, technology, transportation capacity, and money. According to Coppola (20II), the efforts to reduce the exposure of individuals to the consequences of disasters and the measures taken to address the impacts are the goals of disaster management. In this context, Tomasini and Van Wassenhove (2009) argue that disaster management is the result of a long and structured project of strategic processes (preparedness) that are strongly related to the successful execution (response). Disaster management consists of four phases: mitigation, preparedness, response, and rehabilitation. The preparedness and response phases have a strong connection, namely the preparedness discusses the strategy whose implementation is the response (Tomasini and Van Wassenhove, 2009). In this paper, we will consider the preparedness and mitigation activities, in the sense that clusters methodology does not need to be implemented when a disaster happens, but when preparedness plans or risk mitigation strategies are being developed. Tomasini and Van Wassenhove (2009) conceptualize the preparedness phase as "put an end to firefighting", because good preparedness leads to much more effective responses because they were planned beforehand.

There are a lot of important papers that considers this phases, as: Beamon and Kotleba (2006a,b),Chang et al. (2007), Kóvacs and Spens (2007), Jahre and Jensen (2010), Rodrigues et al. (20I2), among others. Many of these papers focused exclusively on planning, policies, and procedures, as related by Overstreet et al. (20I I). In the same sense of our work, Balcik and Beamon (2008) present a relief mission life cycle for disaster inspired in Beamon (2004) and Thomas (2004). This work turns to the region of clustering and risk analysis proposed in the first item of the Logistics Process Model of Relief in International Disasters (MLSCl) of Tufinkgi (2006), which consists of three functions: (i) determine the profile of the length of each disaster, based on the analysis of data obtained from the past disasters. The profile can be identified through a historical analysis; (ii) identify threatened regions and main threats, resulting in different scenarios regarding the impact of different types of disasters, resources and projected needs; (iii) the combination of information obtained from the performance of the first two functions allows creating profiles of resources requirements, depending on the region as well as on the type of disaster. Thus, different regions with similar levels of criteria will be gathered to form clusters. When working with a clusters system, it is intended to assist in the strategic coordination in defining priorities and in the share of experiences. A common approach is the risk analysis, which takes advantage that each region or mu- 
nicipality contributes with its knowledge and experience so that, finally, a common understanding returned to the planning can be applied in several regions.

The classical concept of clusters introduced by Porter (1998) refers to a geographic concentration of industries in the same area of trade and its suppliers. These concentrations benefit each member, which are now larger, allowing them, therefore, to work together without their flexibility being affected.

Clusters were introduced into HL in late 2005 as a strategic tool to improve the effectiveness of the humanitarian response by ensuring greater predictability, accountability, and partnership. (OCHA, 20I4). The clustering approach in $\mathrm{HL}$ is an attempt to improve the responsiveness and coordination processes in managing disasters. In the field of humanitarianism, clusters have been suggested as a solution to the lack of coordinated disaster response. Clusters for diverse functions, including sheltering, logistics, and water and sanitation, can be viewed as an effort to achieve functional coordination. The cluster concept involves organizing humanitarian relief according to a number of sectors with a predefined leadership. Clusters were introduced to improve efficiency in the five following key areas: (I) sufficient global capacity to meet current and future emergencies; (2) predictable leadership at a global and local level; (3) strengthen partnerships between UN, NGOs, and local authorities; (4) accountability, both for the response and beneficiaries; and (5) strategic field level coordination and prioritization (Jahre and Navangul, 20I I). In September 2005, the Inter Agency Standing Committee (IASC) agreed to designate global cluster leads, specifically for humanitarian emergencies in nine sectors or areas of activity, as shown in Table I.
On the other hand, there is another approach that treats the clustering methodologies with a computational perspective. In this sense, clustering methodologies are descriptive and are intended to identify, given a particular database, a finite set of natural groupings called clusters based on the similarity of the properties of each sample available (Kogan et al., 2006). In a more specific bibliographical survey, some papers were found that use the clustering methodology by means of historical data. We can highlight papers presented by Liu et al. (2013), in which they interpreted and analyzed images of forest fires and determined a standard procedure for image processing and interpretation. The maximum likelihood method and K-means method was adopted to rapidly determine the sizes and ranges of the burn zones. In a similiarly vein, Li et al. (20/3), investigated the studies about spatial patterns and temporal patterns of the drought characteristics and with utilizing the Principal Component Analysis and $\mathrm{K}$-means clustering methods suggest the division of geographical regions according to the pattern of temporal evolution of droughts. Otherwise Chu et al. (20I2), used the cluster analysis methods: k-means, fuzzy c-means (FCM), hierarchical clustering, and normalized cut and the kernel density estimate (KDE) technique to delineate the trajectory clusters and hotspot areas of multiple typhoon tracks in the Taiwan region. The authors consider that the information could be used in planning for disaster management. Chang et al. (2007), present a two-stage procedure underlying clustering-based hybrid inundation model (CHIM), which is composed of linear regression models and artificial neural networks (ANNs) to build the regional flood inundation forecasting model . In some cases, in the data preprocessing stage, K-means clustering is used to categorize the data points of the different flooding characteristics in the

\begin{tabular}{|l|l|}
\hline Cluster & Lead \\
\hline Camp coordination and Management & UNHCR (for conflict-generated IDPs) \\
\hline Emergency Telecommunications & OCHA for overall process ownership \\
& $\begin{array}{l}\text { UNICEF for data collection } \\
\text { WFP for common security telecommunications } \\
\text { service }\end{array}$ \\
\hline $\begin{array}{l}\text { Early Recovery (Formally called Reintegration } \\
\text { and Recovery) }\end{array}$ & UNDP \\
\hline Emergency Shelter & UNHCR (for conflict-generated IDPs) \\
\hline Health & WHO \\
\hline Logistics & WFP \\
\hline Nutrition & UNICEF \\
\hline Protection & UNHCR (for conflict-generated IDPs) \\
\hline Water and Sanitation & UNICEF \\
\hline
\end{tabular}

Table I: Cluster responsibilities and lead organizations in humanitarian emergencies

ISSN: 07 I8-2724. (http://www.jotmi.org)

Journal of Technology Management \& Innovation (c) Universidad Alberto Hurtado, Facultad de Economía y Negocios. 
study area and to identify the control point(s) from individual flooding cluster(s). Wan (20I2) focused on the landslide problems on a area located at Taiwan, studied as generate a reliable susceptibility map based on digital elevation modeling and remote sensing data through clustering technique. Acosta et al. (20II) propose a tool able to support experts in the discovery of risky areas. It is a tool built on top of a weather database, that implements a semi-supervised data mining approach to discover regions with similar weather observations. Mithal et al. (20I I), provided an overview of the exciting opportunities and challenges in developing and applying data mining approaches to provide critical information for forest and land use management. Also in this context, Race et al. (20I I) used clustering techniques to link sea surface temperatures and hurricane frequencies. Steinbach et al. (2003) presents an alternative clustering-based methodology for the discovery of climate indices is based on clusters that represent regions with relatively homogeneous behavior. The analysis of these papers allowed the identification of different tools used for the development of clusters based on data from natural disasters.Among these tools, the most cited are: K-means fuzzy clustering, C-means and hierarchical methods. In this context, we would like to point out the work by Jahre and Navangul (20II). In their work, the means of supply and service demand forecasting were prepared in the $\mathrm{HL}$ context. Thus, the historical data related to information on humanitarian assistance were considered. This data allow for the understanding and the predicting of the future demand, as well as the identification of the key patterns in terms of the needs and demand response. Studies presented in the literature with a computational perspective, as related above, it are used the clusters methodology only for specific types of disasters, for example, drought, typhoon, fires, flooding, landslide. We were not identified in the literature studies using the approach clusters to identify the frequency of various types of disasters in a given region. Face of this context, this study aims to contribute to the $\mathrm{HL}$ through the use of a methodology to form clusters by analyzing historical data of disasters, using the clustering method as a tool for pattern analysis. The tool can assist in strategic coordination, prioritization and exchange of experiences between cities, suggest a method of prevention and, thus, improve and assist the processes of decision-making regarding the events of $\mathrm{HL}$.

\section{Proposed Methodology}

In this section, we will be presented the proposed methodology for the clusters formation, as well as the computational experiment for validation and verification of the presented model, using for that real data on such natural disasters of the state of Santa Catarina - Brazil. It is considered that the same disaster could reach different municipalities at the same time, requiring the coordination between them for the development of actions of relief or aid. Moreover, the impact of a disaster on a specific municipality may require the assistance of other municipality, either in the form of rescue units, or on loan of equipments, expert assistance or recollection of donations. The operations in these situations may have very specific traits. They are characteristics that make the coordination of these operations very difficult if there is not a standardized system, common for planning and implementing of the actions.

Santa Catarina is one of the 27 States of Brazil, located in the southern region of the country. It is the twentieth largest Brazilian State with an area of $95,346,18 \mathrm{I} \mathrm{km}^{2}$, and the eleventh most populous, with 295 municipalities and 6,248,436 inhabitants. The ocean shore is about $450 \mathrm{~km}$. Its capital and seat of government is the city of Florianopolis, located on the island of Santa Catarina. The main rivers in the State are the Canoas River, Peixe River, and Itajai-Açu River. The state of Santa Catarina has $77 \%$ of its territory above $300 \mathrm{~m}$ altitude and $52 \%$ above $600 \mathrm{~m}$. The southern region has an altitude of 800 to $1800 \mathrm{~m}$, highlighting Santa Catarina as one of the Brazilian States of a stronger set of elevations and depressions of the ground. Lower grounds are characteristic of the coastal region, and the central region is characterized by depression. Entirely located south of the Tropic of Capricorn, located in the southern temperate zone of the planet, the State has a subtropical climate. These conditions vary according to the topography of the area, and in the west and mountainous plateau it is a relatively common occurrence to experience frost and snow, while on the coast the climate is warmer and can reach high temperatures during the summer. To demonstrate an application of the clustering approach in $\mathrm{HL}$, the development was split as follows: (i) apply the clustering methodology to the historical data of accidents in the Brazilian State of Santa Catarina; (ii) identify, for each cluster, the type of relief supplies normally used during the response to the disaste; (iii) show the results of the case study.

\section{Clusters Determination}

In order to developing and verifying the proposed methodology we have used the following tools. A Postgres SQL 8.2 database manager was used for the organization of the database, along with Java I.6 programming language. All used maps are georeferenced maps from IBGE (20I3). We used real data from natural disasters in the Brazilian State of Santa Catarina. This proposal consists in investigating the profiles of the regions with the frequency of the occurrence of disasters with similar characteristics and, therefore, establishes clusters by type of disaster. 


\section{Input Data and Processing}

The proposed methodology considers the data from disasters that occurred in the state of Santa Catarina in the period 2000-2010. This data was obtained from the database of the University Centre for Disaster Studies and Research of Federal University of Santa Catarina (CEPEDUFSC). This database uses information from Santa Catarina's Civil Defense documents, such as the damage assessment form; preliminary notification of a disaster, as well as official documents such as decrees, ordinances, reports and other unofficial documents, such as those that appeared in the press. Initially, the occurrences of natural disasters were separated in accordance to the municipalities of the state. Then, it was necessary to filter the available information, since the data included in the CEPED contain several types of disasters. Thus, only the occurrence of natural disasters was selected from the database, resulting in 3,247 events in this category. Natural disasters were considered, classified according to the Civil Defense (DEFESA CIVIL, 20I3). The disasters are classified by the type of the occurrence, as shown in Figure I.
In general, clustering techniques calculate the matrix partition $\left[\mu_{k j}\right]_{K \times n}$, where ${ }^{\mu_{k j}}$ represents the degree of belonging to j-th point ${ }^{x_{j}}$, of the clustering $C_{k}, \mathrm{k}=\mathrm{I}, \ldots ., \mathrm{K}$. Thus, ${ }^{\mu}{ }_{k j}=$ I if the point ${ }^{x_{j}}$ belongs to $C_{k}$ and $\mu_{k j}=0$, otherwise (Bandyopadhyay, 20l I). To carry out the processing of the information and determine the clusters, we used the K-means algorithm. This algorithm performs a sequence of iterative procedures that form $\mathrm{K}$ compact spherical clusters over input data, with the objective of minimizing Equation I:

(l)

$$
J=\sum_{j=1}^{n} \sum_{k=1}^{K} \mu_{k j} D^{2}\left(z_{k}, x_{j}\right)
$$

There $D^{2}\left(z_{k}, x_{j}\right)$, in our work, is the Euclidean distance of $x_{j} z_{\text {to }} z_{k}$; and $z_{1}, \ldots, z_{k}$ are the centroids of the groups. According to Bandyopadhyay (20I I), the algorithm, first of all, randomly initializes the $\mathrm{K}$ centroids. These are used to partition the data by assigning each point to the cluster of its closest center. Succeeding, for each cluster, the mean value of all the data points assigned to it is computed, and this is considered as the new center. This completes one iteration of the K-means clustering. Next, iteration uses the newly computed centers for reassigning the data points to

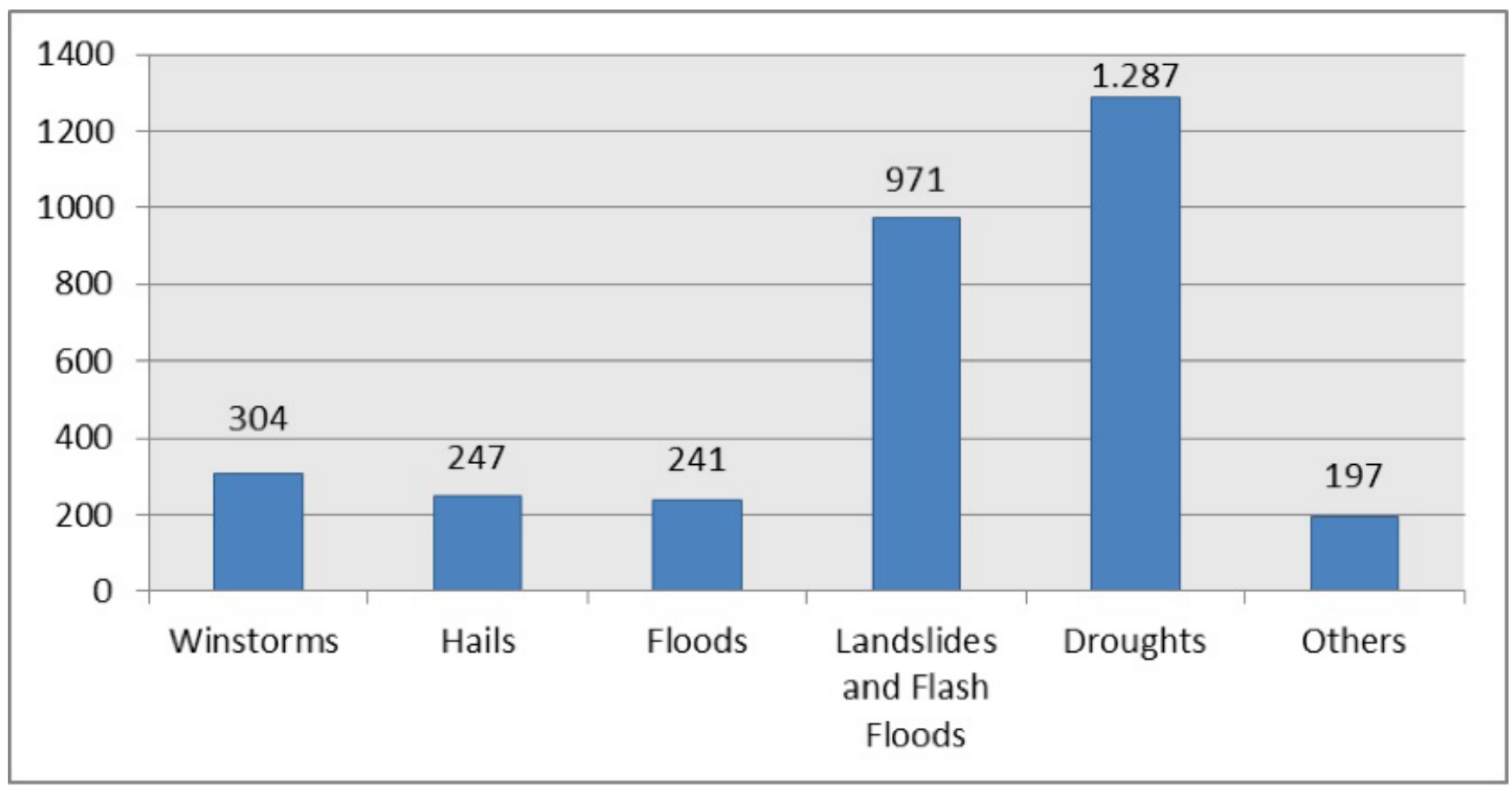

Figure I: Classification of types of disasters registered in Santa Catarina

ISSN: 07 I8-2724. (http://www.jotmi.org)

Journal of Technology Management \& Innovation (c) Universidad Alberto Hurtado, Facultad de Economía y Negocios. 
the $\mathrm{K}$ clusters, and the process continues until the measure of $\mathrm{J}$ falls beneath a certain threshold or a maximum number of iterations have been executed. K-means algorithm is described as follows: Step I: Obtain K centroids, randomly selected; Step 2:Allocate each object in the database to the nearest cluster center;Step 3: Calculate the new centers of the $\mathrm{K}$ clusters by the average of the data points assigned to each cluster; Step 4: Update the cluster centers with the means; Step 5: Compute J; Step 6: Stop, if a stop criteria is satisfied, otherwise return to Step 2.

\section{Resulting Clusters}

To define the number of clusters, we analyzed the mean centroid distribution and the Davies-Bouldin index (Halkidi et al., 200 I), which is based on the measurement of dispersion and a measure of dissimilarity between clusters. On this basis, we decided that the number of four groups responds to the computer test as expected. The results of the K-means algorithm are shown, in a summarized form, in Table 2. The results of the K-means algorithm are plotted, graphically, in Figure 2.

To enable the analysis of the results of the K-means algorithm, we prepared the graph shown in Figure 3, which represents the average of each disaster per cluster compared to the overall average. Furthermore, we obtained the map of the State of Santa Catarina with the geographical distribution of the clusters, as shown in Figure 4.

\begin{tabular}{|c|c|c|c|c|c|c|c|c|}
\hline \multirow{2}{*}{ Cluster } & \multicolumn{6}{|c|}{ Occurrence of Events } & \multirow{2}{*}{ Total Events } & Municipalities \\
\cline { 2 - 8 } & Windstorms & Hail & Floods & Landslides and flash floods & Droughts & Others & Total \\
\hline 1 & 87 & 73 & 22 & 100 & 845 & 33 & 1160 & 90 \\
\hline 2 & 125 & 101 & 133 & 316 & 174 & 36 & 885 & 54 \\
\hline 3 & 35 & 32 & 33 & 201 & 145 & 78 & 524 & 42 \\
\hline 4 & 57 & 41 & 53 & 354 & 123 & 50 & 678 & 108 \\
\hline
\end{tabular}

Table 2 - Results of the K-means algorithm

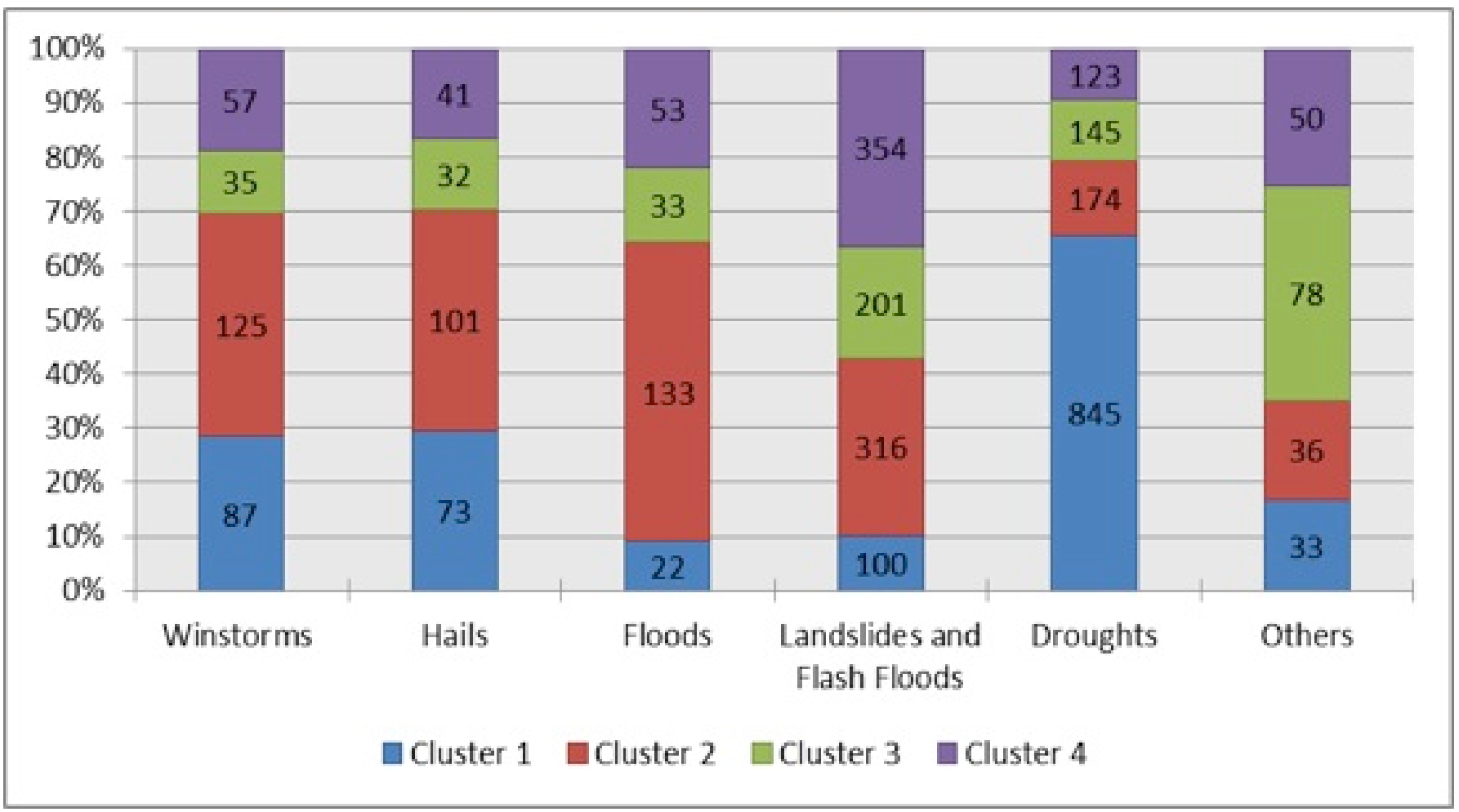

Figure 2: Characterization of the clusters

ISSN: 07 I8-2724. (http://www.jotmi.org)

Journal of Technology Management \& Innovation (c) Universidad Alberto Hurtado, Facultad de Economía y Negocios. 


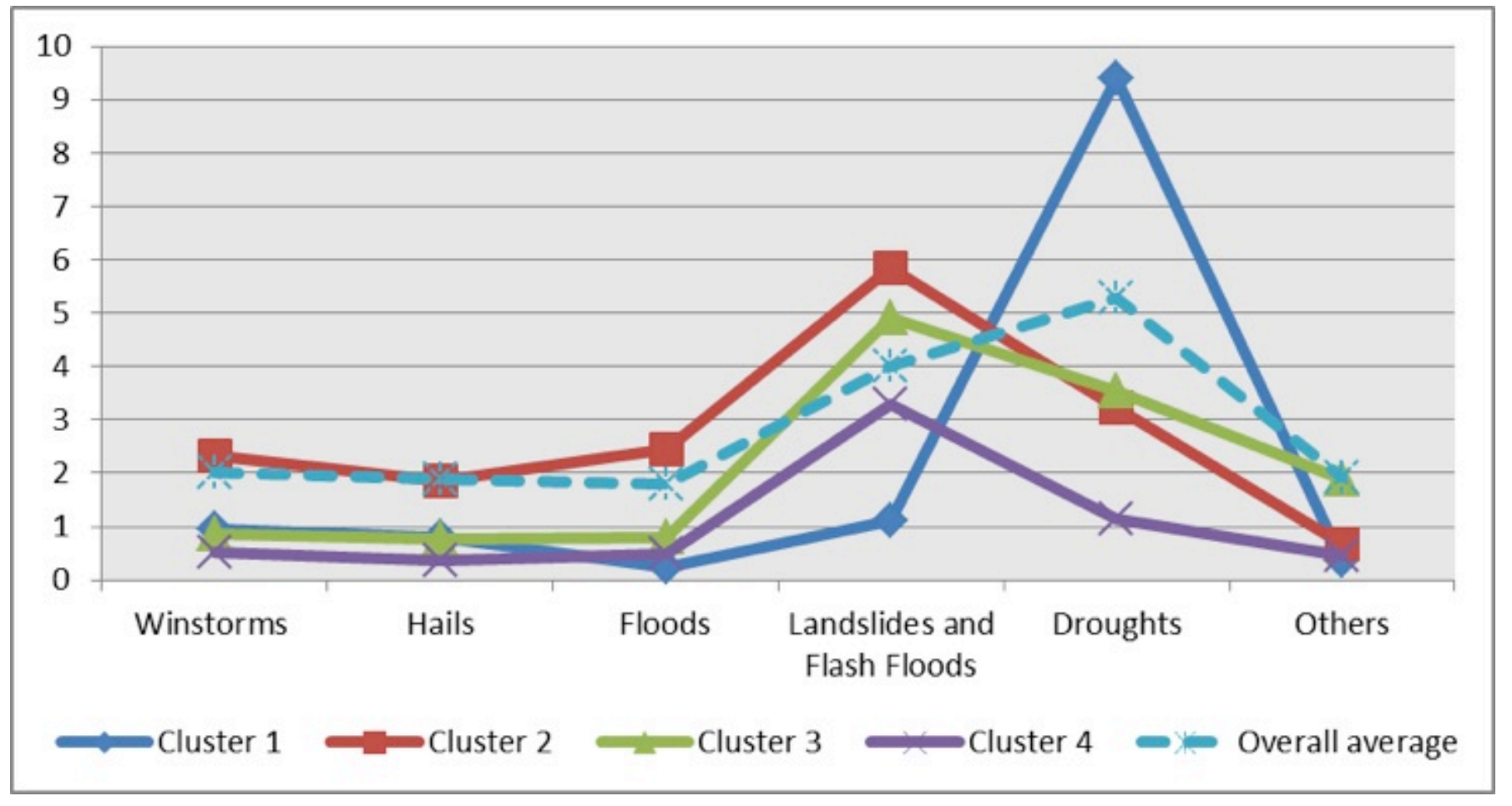

Figure 3:Average of disasters per cluster and overall average

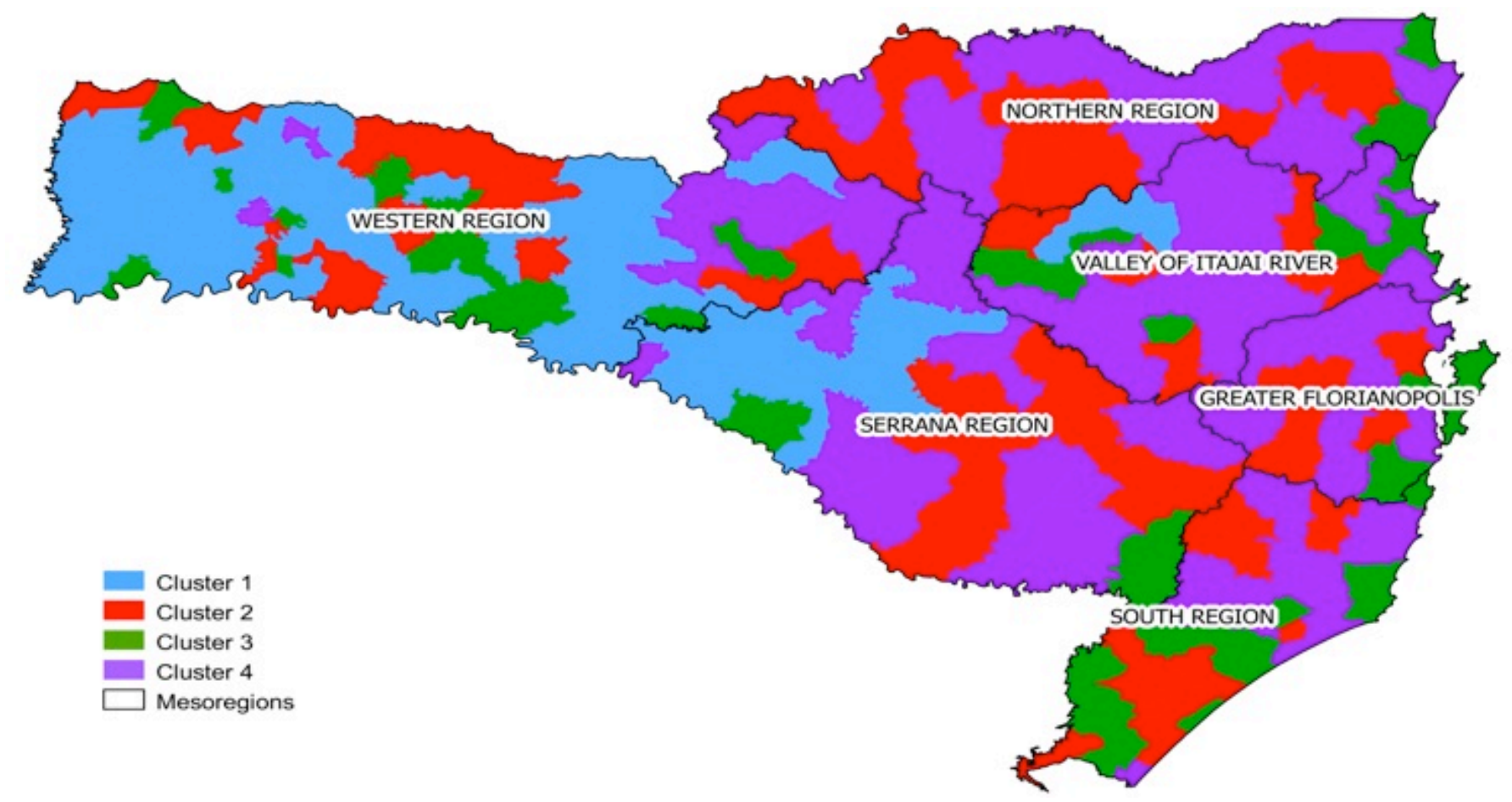

Figure 4: Geographic distribution of the clusters 
Based on Figures 2, 3, and 4, we can conclude that:

- $\quad$ Cluster $I$ is the main one in drought events. In Figure 7 it is possible to identify that the average drought events is above the overall average for this disaster. For other types of disasters, the values are below the overall average. According to Figure 8 , we note that the geographic distribution of this group is concentrated in the western part of the state. The drought events formed a particular cluster, due to its higher rate of recurrence.

- Cluster 2 differs by having municipalities with the occurrence of disasters with greater frequency of windstorms, landslides, and flash floods and floods. In terms of flooding, this is the most critical cluster representing $37.05 \%$ of all occurrences.

- Cluster 3 is characterized by a smaller number of affected municipalities, but it has the second highest average events characterized as floods, with a frequency concentrated in specific areas. According to Figure 8, this cluster includes the municipalities along the coast of the state.

- $\quad$ Cluster 4 shows the largest number of municipalities affected by landslides and flash floods, but it has the lowest average in the other events. This cluster covers the largest number of municipalities that have a low frequency of disasters.

We can also note that the most significant types of disasters in the State have peculiar characteristics and are distinct from each other. The occurrences of droughts are heavily concentrated in the west of Santa Catarina, where most municipalities are involved in agricultural activities. Therefore, this event causes high economic losses to the region. Most of the municipalities affected by floods are mainly located in the region known as the Valley of Itajai River; the region of the State Capital, Florianopolis; and the Northern region of the State. Thus, the impact generated reaches the more urbanized areas. The urbanization process that results in several implications and the disorderly occupation exacerbates the impacts caused by the floods. We can see that in the State of Santa Catarina the most representative events are floods and droughts.

\section{Determining the Relief Supplies}

In this section, we demonstrate how the definition of clusters influences the standardization of preparedness procedures that can be followed by relief organizations to contribute to the response of the disaster. To illustrate the determination of goods, we monitored the events in the State of Santa Catarina in January-July 2013. In this period, there was an important occurrence marked by floods in cluster 4. The determination of the need for goods continues in the clustering step and passes through the phases of data interpretation and the definition of disasters by region. The occurrence of floods in cluster 4 has consequences such as damage to property, damaged or destroyed houses, homeless, lack of drinking water, and destruction of farm land. Thus, the need arises for food products (food parcels for families who have not had their homes destroyed and food parcels of ready products for consumption, on the otherwise), household equipment, kits of hygiene products, cleaning products, bedding and water treatment products. According to these needs, the standardization of emergency kits has been established, as shown in Table 3.

\section{Response to a Disaster in the Brazilian State of Santa Catarina}

There are records of floods in the State of Santa Catarina since 1852, when the Itajai River reached 16 meters above the normal level. In the last 40 years, Santa Catarina presented a history of disasters that has had prominence in the national scope, especially those related to floods: as disaster of 1983, in the Valley of Itajai River, where there were 49 deaths and 198,000 homeless; disaster of 1984, in the Valley of Itajai River, where there were 16 deaths and

\begin{tabular}{|c|l|l|}
\hline Kit & Item & Cluster \\
\hline $\mathrm{I}$ & Drinking water & $\mathrm{I}, 2,3$ and 4 \\
\hline 2 & Food parcels of ready products for consumption & 2,3 and 4 \\
\hline 3 & Food parcels & $\mathrm{I}, 2,3$ and 4 \\
\hline 4 & Water treatment products & 2,3 and 4 \\
\hline 5 & Hygiene products & 2,3 and 4 \\
\hline 6 & Cleaning products & 2,3 and 4 \\
\hline 7 & Bedding products for singles & 2,3 and 4 \\
\hline 8 & Bedding products for couples & 2,3 and 4 \\
\hline 9 & Tents & 2,3 and 4 \\
\hline
\end{tabular}

Table 3:Aligning the Kits with Clusters

ISSN: 07I 8-2724. (http://www.jotmi.org)

Journal of Technology Management \& Innovation (c) Universidad Alberto Hurtado, Facultad de Economía y Negocios. 
220,000 homeless; disaster of 2008 , where $33 \%$ of the State territory was affected and caused 135 deaths and 80,000 homeless, and more than 2 million people were affected. In all these disasters, the cities were completely submerged. It should be noted that the hardest hit are the very poor people who live in the areas most often affected. In these cases, there was always human solidarity, government and military aid, participation of volunteers, and donors, among others. However, it takes much more than that. It is necessary to conduct preventive operations, disaster relief, rehabilitation, and aims to prevent or minimize the effects of disasters, preserving the welfare of the population and to restore social normality. In this direction, we propose to demonstrate the applicability of this methodology approach in a case study involving a disaster in Santa Catarina. We considered for the case study, the events that took place during the months of June and July 2013 in the State. In this event, heavy rains hit the Northern Region of Santa Catarina (cluster 4), resulting in floods, landslides, and flash floods. Even being characterized as a small event, it serves to illustrate the proposed methodology. In the begging of the June 2013 , it started raining in the region of the cluster 4. At the end of June, the municipalities requested assistance. Figure 5 shows the Life cycle of the disaster.

The process of activities used to attend to the disasters in these municipalities was operationalized in five steps:

i. The first step consists in the forecast, where the monitoring management announced the possibility of a disaster due to an adverse event that was in progress. According to the Figure II, this phase lasted from June I5 to June 23 .

ii. In a second step, actions were carried out relating to the mapping and rescue of victims.

iii. In the third step, the analysis of the affected municipalities was performed by using a local and regional assessment to verify the situation and to calculate the number of homeless, assess the damage to the infrastructure in the region, the use of a contingency plan and identifying which municipalities were in an emergency situation. Steps 2 and 3 were conducted early on June 24 . iv. In the fourth phase, requests for assistance were made, in accordance with the verification of the number of affected families that happened on June 26 . The orders were placed on June 27 and the delivery of relief items occurred on June 28.

v. In the fifth step, the complementation to the actions of assistance was carried out, according to the evolution of the disaster and the identified needs. Thus, new orders were placed and the assistance happened on July 2 . As described in Table 3, the items requested for the cluster 4 were: kit 2, 3, 4, 5, 6, and 7. Since the relation with the suppliers of these items was already established, the items delivery was made within 24 hours.

Analyzing the life cycle of the disaster, we can highlight:

- Preparedness phase:This phase is conducted continuously, even when not forecast a disaster. However, the preparedness intensifies when there is confirmation of an event. In this case, preparedness operation was intensified since the rainy started until the declaration of the emergency situation. This is the step that identifies the needs and the recipients based on the specific characteristics of the occurrence. According to the life cycle of a relief mission (Beamon, 2004), in this phase few resources are needed and the time required for the preparedness phase can take several months. In this case, considering only the decisions of the preparedness operational level, this step took fewer than 12 days.

- Response phase:This phase lasts from the elaboration of the orders until the delivery of supplies. Requests for goods, in general, are made within 36 hours from the onset of a disaster (Thomas, 2007). Considering that we already had advance information on the types of relief goods for this cluster, this response phase was made within 24 hours, which is considered appropriate, taking into account that the distance from the suppliers to the affected municipalities is approximately $300 \mathrm{~km}$. The second assistance was required due to the continuity of rainfall, which was requested four days after the first receipt and the delivery of the orders was executed within just one day.

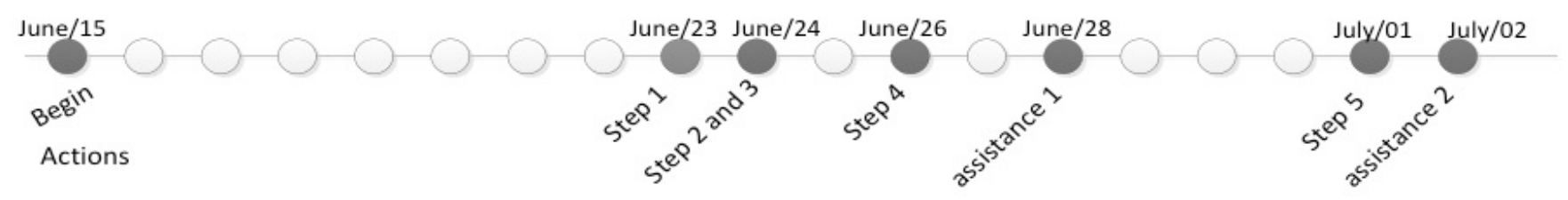

Figure 5: Life cycle of the disaster

ISSN: 07 I8-2724. (http://www.jotmi.org)

Journal of Technology Management \& Innovation (c) Universidad Alberto Hurtado, Facultad de Economía y Negocios. 
The good performance of the response phase was impacted by the identification of the clusters and relief goods that have provided the minimizing of the delivery time.According to the results shown in this case study, we conclude that the determination of the frequency of various types of disasters in a given area may help to standardize a method to prepare for disasters and improve decision making in HL. For each cluster, experience and knowledge can be shared and can become the basis for the integrated planning in the preparedness of the logistic processes relating to the imminence of a disaster.

\section{Concluding Remarks}

In this paper there were presented some concepts involved in $\mathrm{HL}$ and Disaster Management in order to locate the focus of the research.There were discussed concepts and features of a clusters system having the intention to verify the application of the clusters algorithm to profile municipalities affected by natural disasters.

In this work, due to the unavailability of data, we do not take into account the intensity or geographic area affected by natural disasters, as well as costs and number of people affected to data analysis. This demonstrates the weakness in Brazilian public policies that address planning for humanitarian crises. Thus, another question which this paper aims to contribute is to demonstrate the importance of having methodologies keepers of historical data against natural disasters.

Thus the responsible organizations will be able to develop standards for a different form of prevention method, that is, it is verified the profile of each cluster and the decision making regarding which method can be adapted to the groups of municipalities considering the typical behaviour of this group. For each of the clusters of municipalities, the experiences and knowledge can be shared, which could serve as a basis for integrated planning, aiming the preparation and the logistics processes on the imminence of the disasters.

It can be verified that the proposed methodology corresponds to the expectations and brings satisfactory results. These results could be either used as a previous step or as an input data for a big process, which aims to identify potential donors or form partnerships with suppliers during the pre-disaster phase, since it could be useful to assist in evaluating the kind of products required for each type of disaster, prediction of demand and generating inventories.

The contribution of this work consists in proposing a clustering methodology that operates in the processing of historical disaster data in order to form patterns and clusters. This methodology should be considered together with a sequence of procedures that include mapping activities by preparing for a disaster, strategic planning for the acquisition of relief supplies, and collaborative relationship with suppliers. As a result, we have a greater responsiveness to the disaster through standardization, predictability, accountability, and partnership. In this sense, the proposed approach can represent a prerogative to improve the humanitarian response to disasters. We suggest further studies in order to update the data on disasters in order to promote continuously new evaluations.

\section{Acknowledgements}

The authors acknowledge the body of specialists from CEPED/UFSC and the financial support from these Brazilian research agencies: CNPq, CAPES, and Fundação Araucária. 


\section{References}

ACOSTA, M. Gonçalves, M. and Vidal, M.E. (20I I). CAREY: Climatological control of emergency regions. OTM Workshops, Springer-Verlag Berlin Heidelberg. LNCS 7046, p.494503. DOI: I 0.1007/978-3-642-25I26-9_6I. ISSN 0302-9743. ISBN 978-3-642-25I 26-9.

BALCIK, B. and Beamon, B.M. (2008), Facility location in humanitarian relief. International Journal of Logistics: Research and Applications, II.2, p.I0I-12I. DOI: I0.1080/I367556070/56/789

BANDYOPADHYAY, S., (20II). Genetic algorithms for clustering and fuzzy clustering. WIREs Data Mining and Knowledge Discoveryl, p.524-53I. DOI: 10.1002/widm.47

BEAMON, B.M. (2004), Humanitarian relief chains: issues and challenges, Proceedings of the 34th International Conference on Computers \& Industrial Engineering, San Francisco, CA, USA.

BEAMON, B.M. and Kotleba, S.A. (2006a), Inventory management support systems for emergency humanitarian relief operations in South Sudan, International Journal of Logistics Management, I7.2, p. I87-2/2. DOI: http://dx.doi. org// 0.1 I08/095740906/0689952

BEAMON, B.M. and Kotleba, S.A. (2006b), Inventory modelling for complex emergencies in humanitarian relief operations, International Journal of Logistics: Research and Applications, 9.I, p. I-I8. DOI: I0. I080//3675560500453667

CHANG, M., Tseng, Y. and Chen, J. (2007), A scenario planning approach for the flood emergency logistics preparation problem under uncertainty, Transportation Research: Part E, 43.6,p. 737-54. DOI: 10.1016/j.tre.2006.10.013

CHU H. J., Liau, C. J., Lin C.H. and Su, B.S. (20I2).Integration of fuzzy cluster analysis and kernel density estimation for tracking typhoon trajectories in the Taiwan region. Expert Systems with Applications, 39.10,p. 945I-9457. DOI: 10.1016/j.eswa.2012.02.114

COPPOLA, D. P. (20II) Introduction to International Disaster Mangement. 2nd Ed. Butterworth-Heinemann. ISBN- I0: 0I 2382 I746 | ISBN- |3: 978-012382 I 744

DEFESA CIVIL (20I3). Available: www.defesacivil.gov.br. [Acessed June,20I3]
IBGE (20I3) Available: www.ibge.gov.br.[Acessed June,20I3] JAHRE, M. and Jensen, L. M. (2010). Coordination in humanitarian logistics through clusters. International Journal of Physical Distribution \& Logistics Management, 40.8/9,p. 657674. DOI (Permanent URL): I0.1 I08/0960003 I0I I0793 I9

JAHRE, M. and Navangul, A. K. (20I I) Predicting the unpredictable - Demand Forecasting in International Humanitarian Response. In: Proceedings of the 23rd Annual NOFOMA Conference. Harstad, Norway, p. 265-28I.

KOGAN, J., Nicholas, C. and Teboulle, M. (2006). Grouping Multidimensional Data: Recent Advances in Clustering. Berlin:Springer. ISBN-I 0 3-540-28348-X Springer Berlin Heidelberg New York; ISBN-I 3 978-3-540-28348-5 Springer Berlin Heidelberg New York

KOVÁCS, G. and Spens, K. M. (2007). Humanitarian logistics in disaster relief operations. International Journal of Physical Distribution \& Logistics Management, 37.2, p.99-I I4. DOI (Permanent URL): I0.I I08/096000307I 0734820

LI, Bin ; Su, Hongbo ; Chen, Fang ; Li, Shenggong ;Tian, Jing ; Qin, Yuchu ; Zhang, Renhua ; Chen, Shaohui ;Yang, Yongming and Rong, Yuan (2013). The changing pattern of droughts in the Lancang River Basin during 1960-2005. Theoretical and Applied Climatology, I I I.3 p.40 I-4I5. DOI 10.1007/s007040I2-0658-2

LIU, C. ; Kuo, Y. and Chen, C.-W. (20I3). Emergency responses to natural disasters using Formosat-2 high-spatiotemporal-resolution imagery: forest fires . Natural Hazards, 66.2,p. I037-I057. DOI 10.1007/s I 1069-0| 2-0535-4

MEIRIM, H. (2007). Logística humanitária e logística Empresarial, mmrbrasil. Available: www.mmrbrasil.com.br. [Accessed April, 20 I0].

MITHAL,V., Garg, A., Boriah, S., Steinbach,M., Kumar, V., Potter, C., Klooster, S.A. and CastillaRubio, J.C. (20II). Monitoring global forest cover using data mining. ACMTIST 2.4, p.36. DOI: 10.1007/978-3-642-25|26-9

OCHA (2014) Available: http://www.unocha.org/whatwe-do/coordination-tools/cluster-coordination [Accessed Jan,20I4]

OVERSTREET, R.E., Hall, D., Hanna,J. B., Rainer Jr., R. K.(20I I). Research in humanitarian logistics. Journal of Humanitarian Logistics and Supply Chain Management. I.2, p. I I4-I3I.DOI (Permanent URL): | 0. I I08/2042674 I I I I I5842 I 
PORTER, M.E. (1998). Clusters and the new economics of competition. Harvard Business Review,76.6,p. 77-90.

RACE, C., Steinbach, M., Ganguly, A., Semazzi, F.H.M. and Kumar, V. (20II). A knowledge discovery strategy for relating sea surface temperatures to frequencies of tropical storms and generating predictions of hurricanes under 2 Ist-century global warming scenarios. In: CIDU, p. 204-212. . DOI: 10.1007/978-3-642-25/26-9

THOMAS, A. (2004). Elevating Humanitarian Logistics. International Aid \& Trade Review.

THOMAS, A. (2007). Enabling disaster response. Institute Fritz. Available: http://www.fritzinstitute.org/index.htm. [Accessed June, 20I3].

TOMASINI, R. and Van Wassenhove, L. (2009). Humanitarian logistics. Insead Business Press. ISBN-10: 0230205755 | ISBN-I 3: 978-0230205758

TUFINKGI, P. (2006). Logistik im kontext internationaler katastrophenhilfe: Entwicklung eines logistischen referenzmodells für katastrophenfälle.Ed. Haupt Verlag. Bern. Stuttgart Wien. ISBN 13:378-3-258-07036-0. ISBN 10:3-25807036-9.

WAN, S. (20I2). Entropy-based particle swarm optimization with clustering analysis on landslide susceptibility mapping. Environment Earth Science. 68, p.1349-1366. DOI 10.1007/ s|2665-0|2-1832-7 